\title{
The assessment of prosthetic needs of ESRD patients and the general population in Poland on the basis of the Eichner classification and teeth number: A brief, preliminary report
}

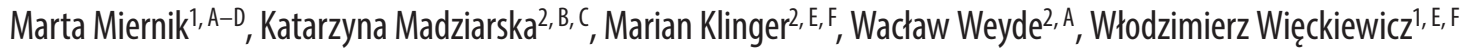 \\ ${ }^{1}$ Department of Prosthetic Dentistry, Wroclaw Medical University, Poland \\ ${ }^{2}$ Department of Nephrology and Transplantation Medicine, Wroclaw Medical University, Poland \\ A - research concept and design; $\mathrm{B}$ - collection and/or assembly of data; $\mathrm{C}$ - data analysis and interpretation; \\ $D$ - writing the article; $E$ - critical revision of the article; $F$ - final approval of article
}

Address for correspondence

Marta Miernik

E-mail:marta_miernik@onet.eu

Funding sources

None declared

Conflict of interest

None declared

Received on August 24, 2015

Revised on January 25, 2016

Accepted on May 13, 2016

\section{Abstract}

Background. End-stage renal disease (ESRD) patients are considered as a group of high risk of oral cavity diseases. One of the determinants of alveolar bone loss and increased teeth mobility in ESRD patients might be the bone abnormalities associated with chronic kidney disease-mineral and bone disorder (CKD-MBD).

Objectives. The aim of the study was to compare the general health condition, number and location of teeth in a group of ESRD patients with the group of peers from general population and revealing the risk factors of tooth loss.

Material and methods. The ESRD group included 63 patients, 23 females and 40 males, undergoing dialysis with a mean age of $62.4 \pm 15.6$. The general population sample consisted of 37 people, 20 females and 17 males, applying for general practitioner visit, with a mean age of $65.5 \pm 11.1$. All the participants were using just public health care insurance. The data analysis was based on anamnesis, history of CKD, selected biochemical parameters of blood tests and clinical examination.

Results. There was no statistical difference in the prosthetic needs of patients undergoing dialysis and the general population. In both groups the situation is alarming.

Conclusions. The new procedures are needed to develop complex health care for ESRD and general population patients, emphasizing prophylaxis of tooth-loss and prosthetic treatment in order to maintain good level of life quality.

Key words: general population, prosthetic needs, Eichner classification, teeth number, ESRD

DOI

10.17219/acem/63155

Copyright

Copyright by Author(s)

This is an article distributed under the terms of the

Creative Commons Attribution Non-Commercial License

(http://creativecommons.org/licenses/by-nc-nd/4.0/) 
End-stage renal disease (ESRD) patients are considered to be a group of high risk of oral cavity diseases. ${ }^{1}$ Chronic Kidney Disease-Mineral Bone Disorder (CKD-MBD) often affects this group and is usually related to secondary hyperparathyroidism. ${ }^{2,3}$ The bone abnormalities, including the loss of lamina dura and abnormal trabeculation of alveolar bone, may be the cause of tooth loss. The clinical findings are more severe in the group of ESRD patients than in patients with less advanced stadium of chronic kidney disease (CKD), and with time become more noticeable during dialysis. ${ }^{4-6}$ As the quality of life strongly depends on oral health, the dental aspects of ESRD patients should be discussed. According to authors' knowledge, the assessment of the prosthetic needs of ESRD patients and the general population in Poland, based on the Eichner classification, has not been published yet.

\section{Methods}

The sample consisted of 100 patients. The ESRD group included 63 patients, 23 females and 40 males, undergoing dialysis in the Department of Nephrology and Transplantation Medicine at Wroclaw Medical University. The average age of the participants was $62.4 \pm 15.6$. The general population group consisted of 37 people, 20 females and 17 males, who applied for general practitioner visit at one of the public ambulatory care units in Wrocław. The mean age of the participants was $65.5 \pm 11.1$. Both groups were covered by public medical insurance.

The data analysis was based on recollecting the history of CKD, selected biochemical parameters of blood tests and clinical examination. Anamnesis included questions about age, sex, weight and height (in order to assess BMI), place of residence, education, smoking habits and general diseases such as diabetes, hypertension, HBV and HCV infections. The medical history of ESRD considered the cause of CKD, time of renal dialysis and dialysis adequacy parameter $(\mathrm{Kt} / \mathrm{V})$. The blood parameters selected in order to evaluate calcium-phosphorus metabolism were: calcium, phosphorus, alkaline phosphatase and parathyroid hormone. The clinical examination focused on the number of teeth and their location in the oral cavity according to the Eichner classification (Table 1).

The statistical analysis was adopted according to Sokal and Rohlf (1995). ${ }^{7}$ The normality of distribution in both groups studied was evaluated with the use of the ShapiroWilk test. In order to assess the statistical significance in the frequency on observations of variables in nominal scale (e.g. the Eichner classification), the $\chi^{2}$ test was used. In the case of variables in the interval and absolute scale the Mann-Whitney test was used to compare the statistical significance between the average and median values in the tested and control groups. Linear correlations between variables were checked by the Spearman's rank correlation index. Differences between the average values in many groups were checked by the Kruskal-Wallis multiple comparison test. Statistical significance was defined as $\mathrm{p}<0.05$. Statistical analysis was performed using STATISTICA v. 10 software.

Ethical approval for the study was obtained from the regional ethics committee for human research, Wroclaw Medical University, according to the Helsinki Declaration.

\section{Results}

There were no significant differences between ESRD and the general population groups in the mean age of patients (ESRD group: 62.4 \pm 15.6; control group: $65.5 \pm 11.1$ ), sex (ESRD group: 23 females and 40 males; control group: 20 females and 17 males), place of residence (ESRD group: town $74.6 \%$ and countryside $25.4 \%$; control group: town $73 \%$ and countryside $27 \%$ ) and smoking habits (ESRD group: non-smokers $87.3 \%$ and smokers $12.7 \%$; control group: non-smokers $81.1 \%$ and smokers $18.9 \%$ ) ( $p>0.05$ ). The significant differences between both groups concerned education, BMI values and general health. The dialyzed patients more often had vocational training $(39.7 \%)(\mathrm{p}=0.009)$ and less often a primary education $(7.9 \%)(\mathrm{p}=0.001)$ in comparison to the control group: $21.6 \%$ and $27 \%$, respectively. The percentage of participants without and with a higher degree in the ESRD group were $27 \%$ and $25.4 \%$, respectively. In the control group, the values were: $32.4 \%$ and $18.9 \%$, respectively. Moreover, overweight patients (BMI $\geq 25)$ were significantly more often found in control group ( $\mathrm{p}=0.006)$. The $54 \%$ of dialyzed patients and about $80 \%$ of control group patients had BMI $\geq 25$. Dialyzed patients significantly more often suffered from diabetes mellitus (33.3\%) $(\mathrm{p}=0.024)$ and hepatitis B and/or C (27\%) $(\mathrm{p}=0.000)$ than control group.

The statistical analysis of clinical examination parameters revealed that there were no significant differences in the number of teeth and the frequency of percentage incidence of the Eichner classification groups between dialyzed and general population groups (Table 2). The average number of teeth in ESRD and general population groups were $13.1 \pm 10.7$ and $13.4 \pm 10.4$, respectively.

In both groups, a correlation was found between the number of teeth and education $(\mathrm{r}=0.325, \mathrm{p}<0.05$; $\mathrm{r}=0.582, \mathrm{p}<0.05$ for ESRD and general population groups, respectively) and an inverse correlation for age $(\mathrm{r}=-0.518, \mathrm{p}<0.05 ; \mathrm{r}=-0.674, \mathrm{p}<0.05$ for ESRD and general population groups, respectively). In the general population, the additional risk factor of tooth-loss was hypertension. The ESRD group revealed correlations between the number of teeth and dialysis adequacy assessed by Kt/V index $(\mathrm{r}=0.319, \mathrm{p}<0.05)$ and the level of calcium in blood samples $(r=0.287, \mathrm{p}<0.05)$. An inverse correlation was observed between the number 
Table 1. Eichner classification

\begin{tabular}{|l|l|}
\multicolumn{2}{|c|}{$\begin{array}{l}\text { Group A. Intermaxillary contact in four occlusal supporting zones } \\
\text { (in the premolars and molars regions) }\end{array}$} \\
\hline A2 & $\begin{array}{l}\text { Two full dental arches } \\
\text { missing teeth }\end{array}$ \\
\hline A3 & Two dental arches with interdentally missing teeth \\
\hline Group B. Intermaxillary contact, not in all occlusal supporting zones \\
\hline B1 & Intermaxillary contact in three occlusal supporting zones \\
\hline B2 & Intermaxillary contact in two occlusal supporting zones \\
\hline B3 & Intermaxillary contact in one occlusal supporting zone \\
\hline B4 & Intermaxillary contact apart from occlusal supporting zones \\
\hline C1 & One dental arch with residual dentition, one edentulous arch \\
\hline G & Two dental arches with residual dentition \\
\hline
\end{tabular}

of teeth and the concentration of alkaline phosphatase $(\mathrm{r}=-0.265, \mathrm{p}<0.05)$. In addition, there was a correlation between the number of teeth and the cause of ESRD - it was observed that patients with glomerulonephritis had significantly more teeth in the oral cavity than other ESRD patients. However, patients with glomerulonephritis had lower mean age than other patients on dialysis, which may explain their higher number of teeth preserved.

\section{Discussion}

The study showed a catastrophic situation in prosthetic needs not just in ESRD group of patients, but also in general population group. Cengiz et al., Brito et al., Castillo et al., Bots et al. and Bayraktar et al. also did not find any statistically important difference in the number of teeth between dialyzed patients and control groups. ${ }^{8-12}$ According to Brito et al., the average number of teeth in hemodialyzed patients with the mean age of $50 \pm 10$ was $17.7 \pm 6.4$, and in patients undergoing peritoneal dialysis with the mean age of $52 \pm 12$ was $17.3 \pm 6.5 .{ }^{9}$ Castillo et al. reported that the mean number of teeth in dialyzed patients with the mean age of $61.5 \pm 18.04$ was $19.8 \pm 8.5 .^{10}$ However, Kanjanabuch et al. indicated that patients undergoing peritoneal dialysis had significantly less teeth than those in the control group. According to those au-
Table 2. The frequency of observations of patients classified to different groups $T$ (A1-C3) according to Eichner index [number of observations $(\mathrm{N})$ and percentage contribution (\%)] in ESRD group $(\mathrm{N}=63)$ and general population group $(\mathrm{N}=37)$ and results of statistical analysis $\left(X^{2}, p\right)$

\begin{tabular}{|c|c|c|c|c|c|c|}
\hline & \multicolumn{2}{|c|}{ ESRD group } & \multicolumn{2}{|c|}{$\begin{array}{c}\text { General } \\
\text { population } \\
\text { group }\end{array}$} & \multirow[t]{2}{*}{$x^{2}$} & \multirow[t]{2}{*}{$\mathrm{p}$} \\
\hline & $\mathrm{N}$ & $\%$ & $\mathrm{~N}$ & $\%$ & & \\
\hline $\mathrm{A} 1$ & 2 & 3 & 1 & 3 & 0.00 & 1.00 \\
\hline$A 2$ & 5 & 8 & 5 & 14 & 1.84 & 0.75 \\
\hline A3 & 4 & 6 & 2 & 5 & 0.10 & 0.76 \\
\hline B1 & 6 & 10 & 1 & 3 & 4.03 & 0.45 \\
\hline B2 & 8 & 13 & 5 & 14 & 0.04 & 0.84 \\
\hline B3 & 4 & 6 & 5 & 14 & 3.56 & 0.06 \\
\hline B4 & 6 & 10 & 2 & 5 & 1.80 & 0.18 \\
\hline C1 & 2 & 3 & 3 & 8 & 2.41 & 0.12 \\
\hline C2 & 17 & 27 & 8 & 22 & 0.68 & 0.41 \\
\hline C3 & 9 & 14 & 5 & 14 & 0.00 & 1.00 \\
\hline
\end{tabular}

thors, the difference in the number of teeth between the two groups is not caused by the changes in the structure of alveolar bone, as in both groups the bone density was comparable. ${ }^{13}$

Teeth maintenance is crucial for maintaining the aesthetics and function of the stomatognathic system. There was no significant difference in the frequency of percentage incidence of the Eichner classification groups, leading to conclusion that number and location of teeth in oral cavity were comparable in test and control groups. However, it should be emphasized that tooth loss is a serious problem. Only $17 \%$ of dialyzed patients had 4 supporting zones in the area of premolars and molars. The rest of the patients had missing teeth in the maxilla and/or mandible, which may influence the efficiency of the masticatory organ and life quality of all the patients. ${ }^{14,15}$ The very limited amount of available research showed that the frequency of prosthetic reconstructions usage among ESRD patients is very low. Musacchio et al. remarked about the existence of a large group of edentulous patients undergoing dialysis, who do not use dentures. ${ }^{16}$ WilczyńskaBorawska et al. assessed the prosthetic needs of dialyzed females with the mean age of $62 \pm 14$ and males with the mean age of $67 \pm 11$ years. The results showed that nearly $70 \%$ of ESRD patients do not have reconstructed teeth deficiencies. ${ }^{17}$ According to Cunha et al., the percentage of patients undergoing dialysis in need of prosthetic treatment is around $80 \% .^{18}$ 
The oral health state of ESRD and general population patients are equally alarming. The possible reason for the high level of prosthetic needs of patients are definitely not the changes related to the end-stage renal disease, but it might be the inadequate Polish social medical insurance system. As there are no procedures encouraging the patient to consider prevention and attend regular check-up visits at dental offices, providing sufficient oral health care is a daunting task. These system deficiencies might have blurred the impact of ESRD specific features reflected by positive correlations of the teeth number with dialysis adequacy, serum calcium concentration, and inverse with alkaline phosphatase activity. It is crucial to examine the dental health of the Polish population in terms of prosthetic needs in order to create a new algorithm to facilitate prevention.

\section{Conclusions}

The new procedures are needed to develop complex health care of ESRD and general population patients in order to maintain a good level of life quality, focusing on prophylaxis of tooth-loss and prosthetic treatment of already existing damage.

\section{References}

1. Dirschnabel AJ, Martins Ade S, Dantas SA, et al. Clinical oral findings in dialysis and kidney-transplant patients. Quintessence Int. 2011;42:127-133.

2. Kidney Disease: Improving Global Outcomes (KDIGO) CKD-MBD Work Group: KDIGO clinical practice guideline for the diagnosis, evaluation, prevention, and treatment of Chronic Kidney Disease-Mineral and Bone Disorder (CKD-MBD). Kidney Int Suppl. 2009;113:1-130.
3. Ghosh B, Brojen T, Banerjee S, et al. The high prevalence of chronic kidney disease-mineral bone disorders: A hospital-based crosssectional study. Indian J Nephrol. 2012;22:285-291.

4. Nickolas TL, Stein EM, Dworakowski E, et al. Rapid cortical bone loss in patients with chronic kidney disease. J Bone Miner Res. 2013;28:1811-1820.

5. Messier MD, Emde K, Stern L, et al. Radiographic periodontal bone loss in chronic kidney disease. J Periodontol. 2012;83:602-611.

6. Frankenthal S, Nakhoul F, Machtei EE, et al. The effect of secondary hyperparathyroidism and hemodialysis therapy on alveolar bone and periodontium. J Clin Periodontol. 2002;29:479-483.

7. Sokal RR, Rohlf FJ. The principles and practices of statistics in biological research. $3^{\text {rd }}$ ed. New York, NY: W.H. Freeman; 1995:887.

8. Cengiz MI, Sümer $P$, Cengiz $S$, et al. The effect of the duration of the dialysis in hemodialysis patients on dental and periodontal findings. Oral Dis. 2009;15:336-341.

9. Brito F, Almeida S, Figueredo CM, et al. Extent and severity of chronic kidney disease patients. J Periodontal Res. 2012;47:426-430.

10. Castillo A, Mesa F, Liébana J, et al. Periodontal and oral microbiological status of an adult population undergoing haemodialysis. Oral Dis. 2007;13:198-205.

11. Bots CP, Poorterman JHG, Brand HS, et al. The oral health status of dentate patients with chronic renal failure undergoing dialysis therapy. Oral Dis. 2006;12:176-180.

12. Bayraktar G, Kurtulus I, Kazancioglu R, et al. Oral health and inflammation in patients with end-stage renal failure. Perit Dial Int. 2009;29:472-479.

13. Kanjanabuch $P$, Sinpitaksakul $P$, Chinachatchawarat $S$, et al. Oral and radiographic findings in patients undergoing continuous ambulatory peritoneal dialysis. J Med Assoc Thai. 2011;94(Suppl 4):106-112.

14. Brennan DS, Spencer AJ, Roberts-Thomson KF. Tooth loss, chewing ability and quality of life. Qual Life Res. 2008;17:227-235.

15. Inukai M, John MT, Igarashi Y, et al. Association between perceived chewing ability and oral health-related quality of life in partially dentate patients. Health Qual Life Outcomes. 2010;8:118.

16. Musacchio $E$, Perissinotto $E$, Binotto $P$, et al. Tooth loss in elderly and its association with nutritional status, socio-economic and lifestyle factors. Acta Odontol Scand. 2007;65:78-86.

17. Wilczyńska-Borawska M, Małyszko J, Cylwik-Rokicka D, et al. Prosthetic status and treatment needs for lost masticatory function in haemodialysis patients. Arch Med Sci. 2012;8:81-87.

18. Cunha FL, Tagliaferro EP, Pereira AC, et al. Oral health of a Brazilian population on renal dialysis. Spec Care Dentist. 2007;27:227-231. 